\title{
Monogenic Mitochondrial Disorders
}

\author{
Werner J.H. Koopman, Ph.D., Peter H.G.M. Willems, Ph.D., \\ and Jan A.M. Smeitink, Ph.D.
}

\begin{abstract}
From the Department of Biochemistry, Nijmegen Center for Molecular Life Sciences (W.J.H.K., P.H.G.M.W.), and the Department of Pediatrics, Nijmegen Center for Mitochondrial Disorders (J.A.M.S.) both at Radboud University Medical Center, Nijmegen, the Netherlands. Address reprint requests to $\mathrm{Dr}$. Smeitink at Nijmegen Center for Mitochondrial Disorders, Radboud University Nijmegen Medical Center, Geert Grooteplein Zuid 10, P.O. Box 9101, 6500 HB Nijmegen, the Netherlands, or atj.smeitink@cukz.umcn.nl.
\end{abstract}

N Engl J Med 2012;366:1132-41.

Copyright (c) 2012 Massachusetts Medical Society.

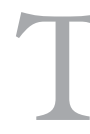
O FUNCTION NORMALLY, HUMAN CELLS REQUIRE ENERGY IN THE FORM of ATP. In many cell types, ATP is primarily generated by mitochondria, which are also key players in other important cellular processes, such as adaptive thermogenesis, ${ }^{1}$ ion homeostasis, ${ }^{2}$ innate immune responses, ${ }^{3}$ production of reactive oxygen species, ${ }^{4}$ and programmed cell death (apoptosis). ${ }^{5}$ Mitochondria contain their own DNA (mtDNA), which encodes 13 mitochondrial proteins, 2 ribosomal RNAs (rRNAs), and 22 transfer RNAs (tRNAs). The replication, transcription, translation, and repair of mtDNA are controlled by proteins encoded by nuclear DNA (nDNA). ${ }^{6,7}$

Mitochondrial dysfunction is not only observed in monogenic mitochondrial disorders but is also associated with more common pathologic conditions, such as Alzheimer's disease,${ }^{8}$ Parkinson's disease, ${ }^{9}$ cancer, ${ }^{10}$ cardiac disease,${ }^{11}$ diabetes, ${ }^{12}$ epilepsy, ${ }^{13}$ Huntington's disease, ${ }^{14}$ and obesity. ${ }^{15}$ In addition, a progressive decline in the expression of mitochondrial genes is a central feature of normal human aging. ${ }^{16}$ It is not entirely clear whether the changes in expression that occur with aging have positive or negative effects on life span. Given the aging of the population in developed societies and the increasing prevalence of conditions such as Alzheimer's disease and diabetes, the investigation of mitochondrial processes and diseases may make a timely contribution to our understanding of the human aging process and its relationship with the above conditions.

Other sources of interference in mitochondrial function include the off-target effects of environmental toxins (e.g., rotenone) and frequently used drugs (e.g., amiodarone, biguanides, haloperidol, statins, valproic acid, zidovudine), anesthetics (e.g., halothane), antibiotics (e.g., chloramphenicol), chemotherapeutic agents (e.g., doxorubicin), and even aspirin (acetylsalicylic acid). ${ }^{17,18}$ Certain drugs may lead more frequently to adverse reactions and side effects in patients with mitochondrial disorders than in healthy persons. ${ }^{17,19}$ The term "mitochondrial medicine"20 refers to approaches that have been developed to manage mitochondrial dysfunction and, directly or indirectly, its consequences. ${ }^{21}$

In the past decade, the analysis of monogenic mitochondrial diseases has considerably advanced our understanding of the cellular pathophysiology of mitochondrial dysfunction. Here we summarize these insights and explain how they can contribute to the rational design of intervention strategies for mitochondrial dysfunction; we present our ongoing research on human mitochondrial complex I deficiency as an example of mitochondrial medicine. This information is preceded by a brief primer on the basics of mitochondrial structure and ATP generation. 
INTERNAL AND EXTERNAL STRUCTURE AND ATP GENERATION

\section{STRUCTURE}

Mitochondrial internal and external structure varies with cell type and metabolic state and often becomes altered during mitochondrial dysfunction (Fig. 1A and 1B). ${ }^{22}$ Net mitochondrial morphology depends on the balance between mitochondrial motility, fission, and fusion. This equilibrium is regulated by dedicated proteins and plays a role in metabolic energy dissipation, turnover of damaged mitochondria, distribution of mitochondria throughout the cell, induction of apoptosis, mitochondrial inheritance during cell division, and defense against aging. ${ }^{23}$ Mitochondria consist of outer and inner membranes that envelop an aqueous compartment, the mitochondrial matrix (Fig. 1C and 1D). The space between the inner and outer membranes is referred to as the intermembrane space. The outer membrane is relatively smooth, whereas the inner membrane contains many matrix-protruding folds (or cristae) that increase the surface area of the inner membrane and have a dynamic structure. ${ }^{22}$ These structural dynamics may serve to regulate mitochondrial metabolism. ${ }^{24}$

\section{ATP GENERATION}

The best-known mitochondrial function is the production of ATP. For this purpose, glucose is converted to pyruvate through the glycolysis pathway in the cytosol (Fig. 1E). Pyruvate can be converted into lactate ${ }^{10}$ or taken up by mitochondria, where it is converted to acetyl coenzyme A (CoA). Acetyl CoA enters the tricarboxylic acid cycle that generates the reduced forms of $\mathrm{NADH}$ and flavin adenine dinucleotide $\left(\mathrm{FADH}_{2}\right)$. Alternatively, fatty acids $^{25}$ and glutamine ${ }^{10}$ can be used as substrates. $\mathrm{NADH}$ and $\mathrm{FADH}_{2}$ fuel the oxidative-phosphorylation system, which consists of five functionally coupled mitochondrial protein complexes. ${ }^{26} \mathrm{NADH}$ and $\mathrm{FADH}_{2}$ are oxidized at mitochondrial complexes I and II, respectively (Fig. 1F). The released electrons are transported to complex III by coenzyme $\mathrm{Q}_{10}\left(\mathrm{CoQ}_{10}\right)$ and then to complex IV by cytochrome $c$, where they are donated to molecular oxygen to form water. The energy released by electron transport is used at complexes I, III, and IV to expel protons $\left(\mathrm{H}^{+}\right)$from the mitochondrial matrix, which establishes a proton gradient across the mitochondrial inner membrane. The latter is associated with an inside-negative inner- membrane potential $(\Delta \psi)$ and a matrix-directed proton-motive force. The proton-motive force is used at complex V to generate ATP, which is transported to the cytosol by the adenine nucleotide translocator. The proton-motive force also sustains many other mitochondrial functions (e.g., ion transport, metabolite exchange, protein import, and mitochondrial fusion). ${ }^{27}$ As a consequence, defects in oxidative phosphorylation often induce multiple cellular aberrations.

MONOGENIC CELL MODELS OF MITOCHONDRIAL DYSFUNCTION

\section{PRIMARY AND SECONDARY DISORDERS}

With the use of mitochondrial proteome analysis, ${ }^{28}$ approximately 1000 genes encoding mitochondrial proteins have been identified in humans (MitoCarta human inventory, Broad Institute). Mitochondrial dysfunction can arise from a mutation in one of these genes (causing a primary mitochondrial disorder) or from an outside influence on mitochondria (causing a secondary mitochondrial disorder). Causes of secondary disorders include viral infections $^{29}$ and off-target drug effects. ${ }^{17,18}$ To date, mutations in 228 protein-encoding nDNA genes and 13 mtDNA genes have been linked to a human disorder (Fig. 2). (For a list of these genes and their associated disease phenotypes, see Table 1 in the Supplementary Appendix, available with the full text of this article at NEJM.org.) Given the preponderance of nDNA-encoded mutations, this review focuses mainly on these genes. A detailed discussion of mtDNA mutations and their associated pathology is provided elsewhere. ${ }^{30-35}$

\section{MUTATIONS AND PHENOTYPE}

Although it is evident that mutations in mitochondrial proteins induce mitochondrial dysfunction, it is less clear how specific genetic defects are linked to dysfunction at the level of cells, organs, and the whole organism. One major difficulty in determining the effects of specific defects is that the consequences of mitochondrial dysfunction are affected by the action of compensatory stress-response pathways. At the cellular level, these responses include mitochondrial biogenesis, increased expression of oxidative phosphorylation proteins, a switch to a more glycolytic mode of ATP production, and the removal of dysfunctional mitochondria by quality-control systems. ${ }^{9}, 36-39$ To complicate matters even further, the substrate sup- 


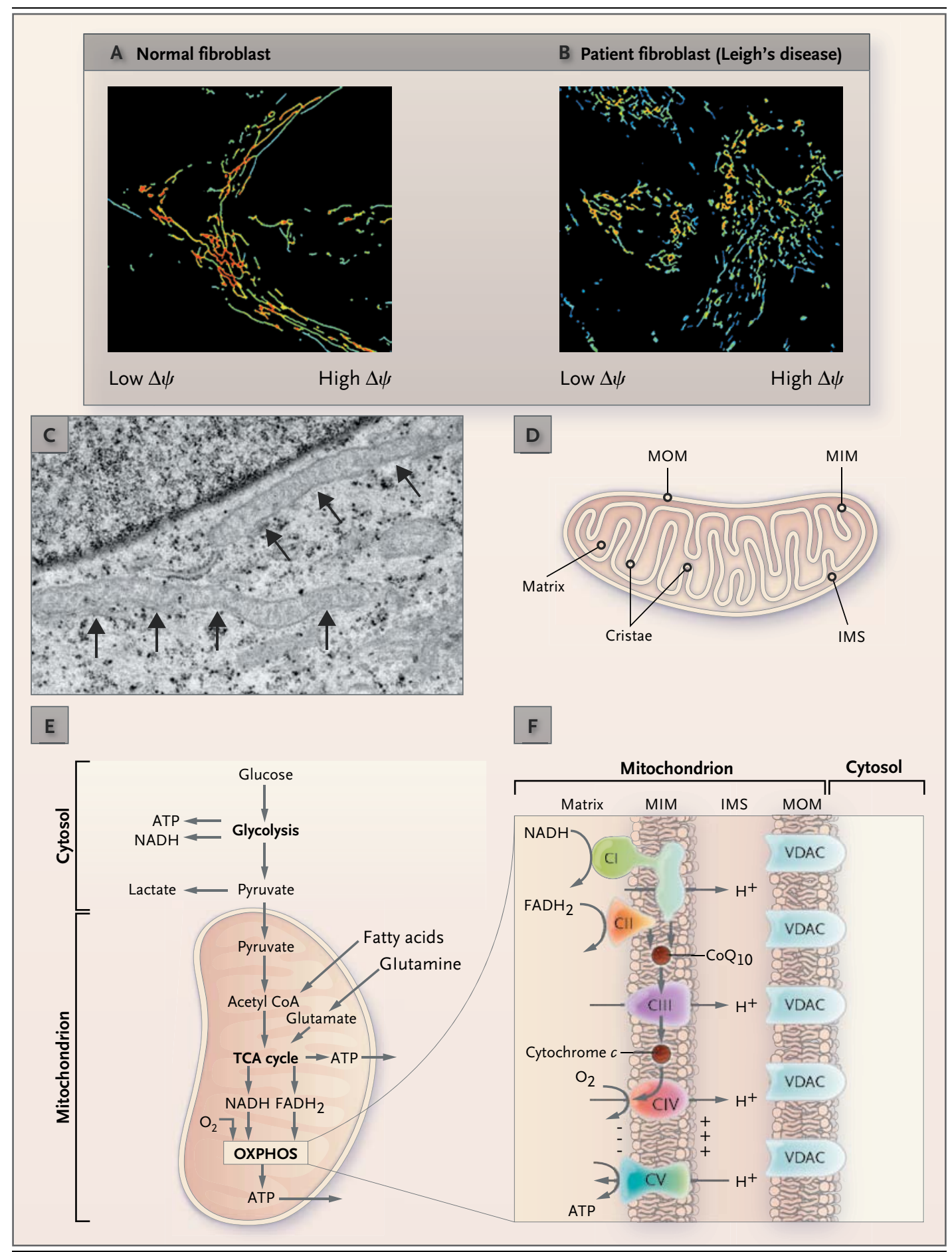

ply, the mode of ATP generation, the level of demand for ATP, mitochondrial dynamics, and the rate of oxidative phosphorylation differ among cell types and tissue types.

These factors increase the likelihood that the various types of tissue are not equally sensitive to mitochondrial dysfunction. ${ }^{27,40}$ At the level of the organism, genetic background - both mitochondrial and nuclear - also modifies the phenotype of human mitochondrial diseases (e.g., as reported by Bénit et $\mathrm{al}^{41}$ ). In this sense, mutations in mitochondrial proteins can evoke pathologic phenotypes specific to a cell, tissue, organ, or patient that are manifested only when a certain threshold 
Figure 1 (facing page). Mitochondrial Structure and ATP Generation.

Panel A shows elongated mitochondria (filaments) in a living skin fibroblast from a healthy person (staining with the mitochondria-specific cation tetramethylrhodamine methyl ester [TMRM] and visualized with fluorescence microscopy). The more intense (red) the TMRM signal, the more negative the mitochondrial membrane potential $(\Delta \psi)$. Panel B shows the fragmented mitochondrial structure in living skin fibroblasts from a patient with a mitochondrial disorder (Leigh's disease) caused by a mutation in NDUFS2, which encodes a subunit of complex I. TMRM staining is less intense (i.e., membrane potential is less negative) than in healthy fibroblasts. In the electron micrograph shown in Panel C, individual mitochondrial filaments (arrows) can be seen in the cytosol of a fixed primary-skin fibroblast from a healthy person. The dark line is the membrane of the cell nucleus. Panel D shows mitochondrial ultrastructure and compartmentalization, highlighting the mitochondrial outer membrane (MOM), mitochondrial inner membrane (MIM), and intermembrane space (IMS). Panel E summarizes the main ATP production pathway in human cells. In the cytosol, glucose is converted into pyruvate, which is subsequently processed in the mitochondrion to acetyl coenzyme $A(C o A)$ and the reduced forms of NADH and flavin adenine dinucleotide $\left(\mathrm{FADH}_{2}\right)$. In addition to using pyruvate as a substrate, the mitochondrion can also use fatty acids and glutamine. Mitochondrial ATP production is carried out by the oxidative phosphorylation (OXPHOS) system, shown at the bottom of Panel E. This system is embedded in the MIM and consists of five multiprotein complexes ( $\mathrm{Cl}$ through $\mathrm{CV}$ ), as shown in Panel F. NADH and $\mathrm{FADH}_{2}$ are oxidized at $\mathrm{Cl}$ and $\mathrm{CII}$, and the electrons released are transported to CIII by coenzyme $\mathrm{Q}_{10}$ $\left(\mathrm{CoQ}_{10}\right)$. The electrons are then transferred to cytochrome $c$ and delivered to CIV, where they react with molecular oxygen $\left(\mathrm{O}_{2}\right)$. TCA denotes tricarboxylic acid. The energy released during electron transport is used to expel protons $\left(\mathrm{H}^{+}\right)$from the mitochondrial matrix across the MIM into the IMS. This creates a proton gradient across the MIM, which is associated with an inside-negative potential. At CV, the energy stored in the proton gradient is used to drive ATP production by allowing the reentry of $\mathrm{H}^{+}$into the matrix. Because of the presence of voltage-dependent anion channels (VDACs), the MOM is ion-permeable.

of mitochondrial dysfunction or cellular demand on mitochondrial metabolism is exceeded. This phenomenon is exemplified by the broad variety of clinical presentations associated with mutations in nDNA-encoded mitochondrial genes (see Table 1 in the Supplementary Appendix).

\section{DEVELOPING A RATIONAL INTERVENTION STRATEGY}

Mitochondrial function is often studied in mitochondrial suspensions that have been isolated from patient cells or tissues with the use of detergent treatment. ${ }^{42}$ However, mitochondrial metabolism in situ is closely linked to that of the cell and is generally associated with submaximal rates of mitochondrial enzyme activity. In addition, the cellular milieu provides for communication among mitochondria, cytosol, and other organelles, and mitochondrial structure is greatly altered during isolation. As a consequence, the functional properties of isolated mitochondria differ considerably from those within the cell. ${ }^{43-45}$

Mitochondrial function can also be investigated in intact (patient) cells. $22,24,25,27,42,46-48$ Here we summarize our ongoing research on complex I deficiency to illustrate how live-cell analysis can be integrated into an approach to the development of treatment strategies (Fig. 3).

Using biopsy specimens from pediatric patients carrying nDNA-encoded complex I mutations, we have cultured primary fibroblast cell lines, which are maintained under standardized conditions. ${ }^{47}$ Cellular and mitochondrial physiology is assessed with the use of fluorescent reporter molecules that are introduced into the cells and analyzed by means of live-cell microscopy (Fig. 4). The results are then compared with those in cells from healthy children. ${ }^{49,52-57}$ Statistical evaluation of 26 physiological variables in 14 control and 24 patient cell lines has revealed that complex I mutations lead to a reduction in the expression of complex I, depolarization of mitochondrial membrane potential, the accumulation of $\mathrm{NADH}$, increased levels of reactive oxygen species, aberrations in mitochondrial structure, and aberrations in the homeostasis of cytosolic and mitochondrial $\mathrm{Ca}^{2+}$ and ATP. ${ }^{58}$ The extent of these aberrations has been correlated with the age of the patient at disease onset and with death from the disease. ${ }^{58}$

These results are currently being used in disease modeling and drug-target prediction to design an intervention strategy focused on the above aberrations. Once a lead compound has been identified, the dependence of its effects on time and concentration can be evaluated at the cellular level to assess structure-activity relationships and its properties of absorption, distribution, metabolism, and excretion (or toxicity)..$^{59}$ In the case of complex I deficiency, lead compounds will then be evaluated in an animal model. ${ }^{57,60}$ Animal models are also available for several other primary and secondary mitochondrial disorders. ${ }^{31,32,56,61,62}$ Once the outcome scores in the animal model are satisfactory, the effects of any compounds that are developed can be evaluated in clinical trials. 


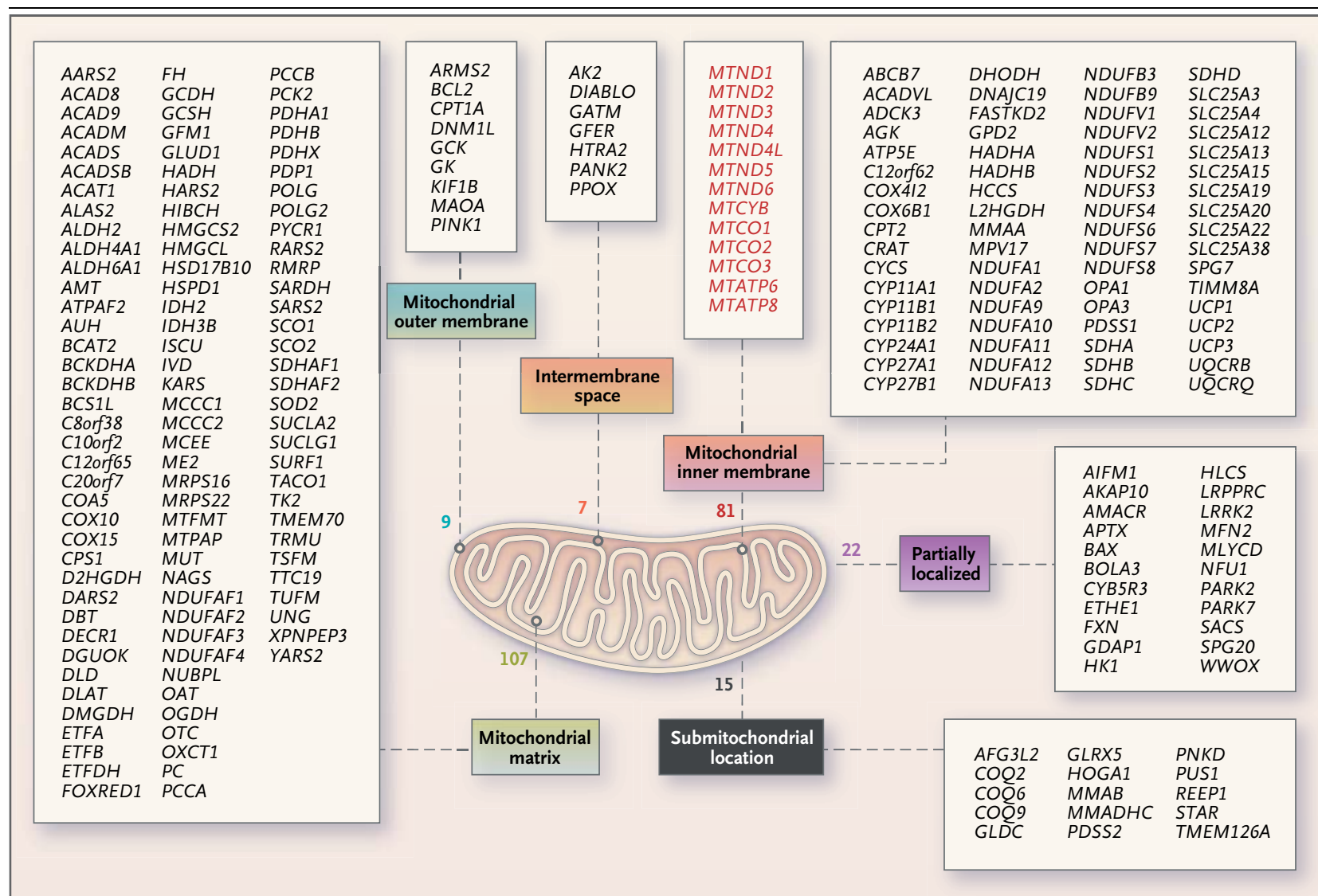

Figure 2. Genes of Mitochondria-Localized Proteins Linked to Disease in Humans.

This list summarizes the currently identified mtDNA-encoded (red) and nDNA-encoded (black) genes associated with mitochondrial diseases in humans when mutated. The genes are categorized according to the predicted localization of their corresponding proteins in the mitochondrial matrix (107 genes), the outer membrane ( 9 genes), the intermembrane space ( 7 genes), and the inner membrane (81 genes). Also included are gene products of unknown submitochondrial location (15 genes) and gene products that partially localize to mitochondria (22 genes). Detailed information about the genes and their associated disease phenotypes is provided in Table 1 in the Supplementary Appendix.

\section{NTERVENTION STRATEGIES}

In a primary mitochondrial disorder, the mutation directly affects the expression level of the corresponding protein, its function, or both, inducing primary cell consequences and secondary cell consequences (Fig. 5). ${ }^{27,63}$ The secondary consequences often constitute part of the adaptive signaling mechanisms.

Adaptations include the partial mitigation of reduced mitochondrial ATP production by increased glycolysis, increases in the cellular levels of mitochondrial proteins and mitochondrial function through mitochondrial biogenesis, and upregulation of the detoxification of reactive oxygen species, triggered by changes in the redox state that were induced by reactive oxygen species. It appears that primary and secondary mitochondrial disorders have similar consequences at the cellular level (Fig. 5). ${ }^{27,58,64,65}$

Four intervention strategies for mitochondrial dysfunction have been described: genetic therapy, the use of small molecules to target mitochondrial dysfunction, metabolic manipulation, and diet and exercise (Fig. 5, and Table 2 in the Supplementary Appendix). Genetic therapy, which is carried out at the preclinical level and focuses mainly on mtDNA-associated disorders, is discussed elsewhere. ${ }^{19,63,64,66,67}$ Small-molecule therapies, metabolic manipulation, and dietary and exercise regimens generally aim to increase the capacity for ATP synthesis, bypass the mitochondrial defect, 


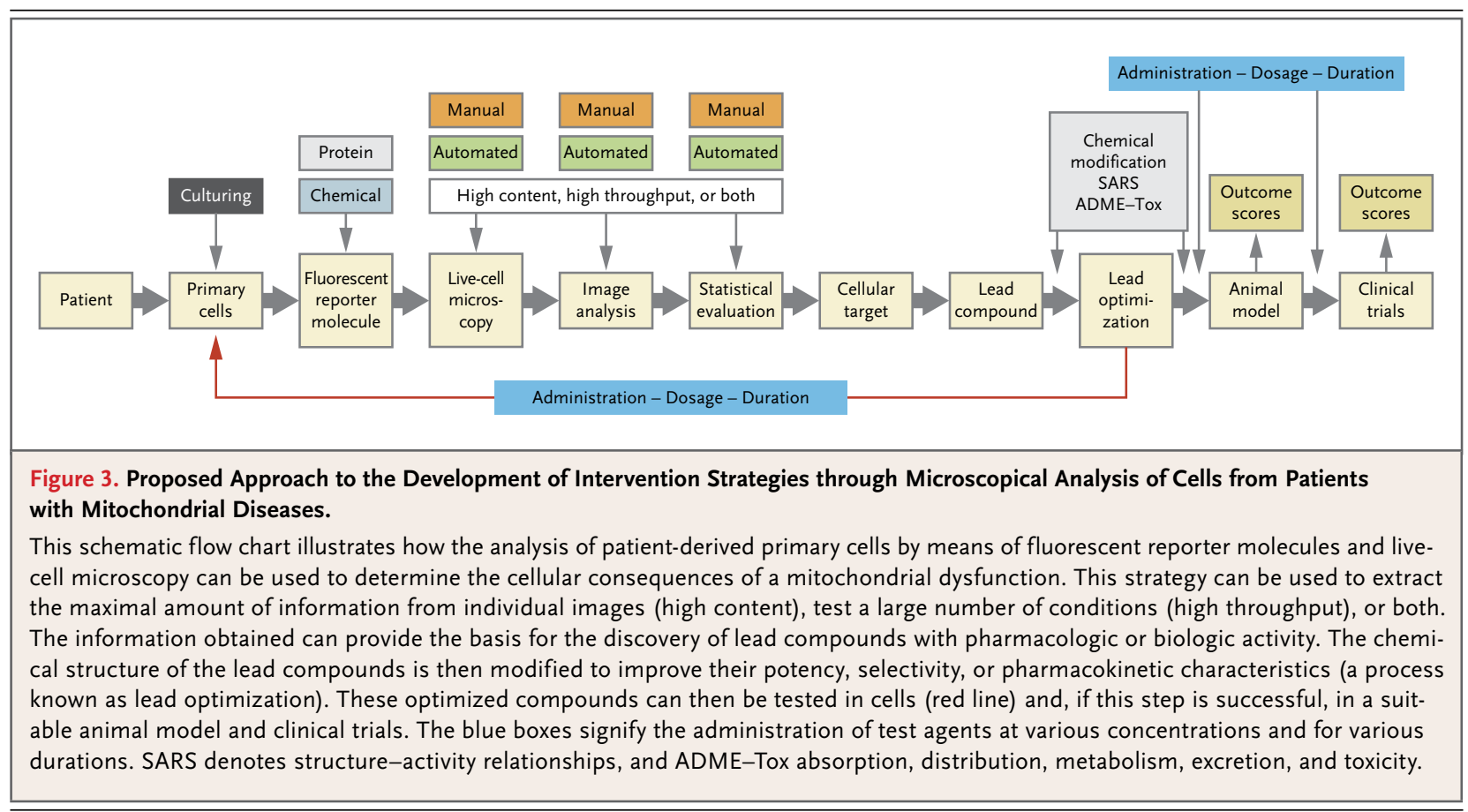

stimulate mitochondrial biogenesis, or reduce levels of reactive oxygen species. ${ }^{66}$ Targeting reactive oxygen species may not be entirely beneficial, however, since they can act as signaling molecules, ${ }^{4,27,48,53}$ in which case their elimination might also have detrimental effects.

\section{MITOCHONDRIA-TARGETED SMALL MOLECULES}

In contrast with membrane-permeable small molecules, which exert their effect throughout the cell, novel therapeutic strategies involve the specific targeting of mitochondria by small molecules (referred to as "cargo"). ${ }^{65,68-74}$ Targeting can be achieved by coupling the cargo to a delocalized lipophilic cation, leading to its accumulation in mitochondria. Several antioxidants have been successfully targeted using the cation approach (e.g., plastoquinones and $\mathrm{CoQ}$ variants). Protein-based cargo can be coupled to a mitochondrial targeting sequence recognized by the mitochondrial protein import machinery. Another strategy involves the use of mitochondria-penetrating peptides, engineered cell-penetrating peptides that target mitochondria on the basis of their membrane potential and lipophilicity (e.g., the antioxidant Szeto-Schiller peptide, SS-31). There are also vesicle-based transporters that target mitochondria through macropinocytosis, endosomal escape, and membrane fusion (e.g., DQAsomes and
MITO-porters). Recently, in a mouse model of mitochondrial lipoamide dehydrogenase (LAD) deficiency, mitochondrial enzyme-replacement therapy mediated by TAT (a transactivating transcriptional activator of human immunodeficiency virus 1) was used to introduce a TAT-LAD fusion protein. ${ }^{75}$

\section{TREATMENT OF MITOCHONDRIAL DISORDERS}

In 2006, a large-scale review of published clinical trials of various treatments for primary mitochondrial disorders revealed no evidence supporting the use of any intervention. ${ }^{76}$ More recently, the results of several trials in which a variety of treatments for mitochondrial disease were studied, including dichloroacetate, vitamins, and a cocktail of specific food components (nutraceuticals), were reviewed. ${ }^{77}$ Although some of these trials showed a positive effect on one or more clinical or biochemical primary end points, none led to the filing of a New Drug Application with the Food and Drug Administration.

The drug idebenone ( $\mathrm{CoQ}_{10}$ variant) has been approved for the treatment of Friedreich's ataxia. ${ }^{41}$ A large multicenter, randomized, placebocontrolled trial of idebenone in patients with Leber's hereditary optic neuropathy revealed that patients with discordant visual acuities were the most likely to benefit from this treatment. ${ }^{78}$ In 


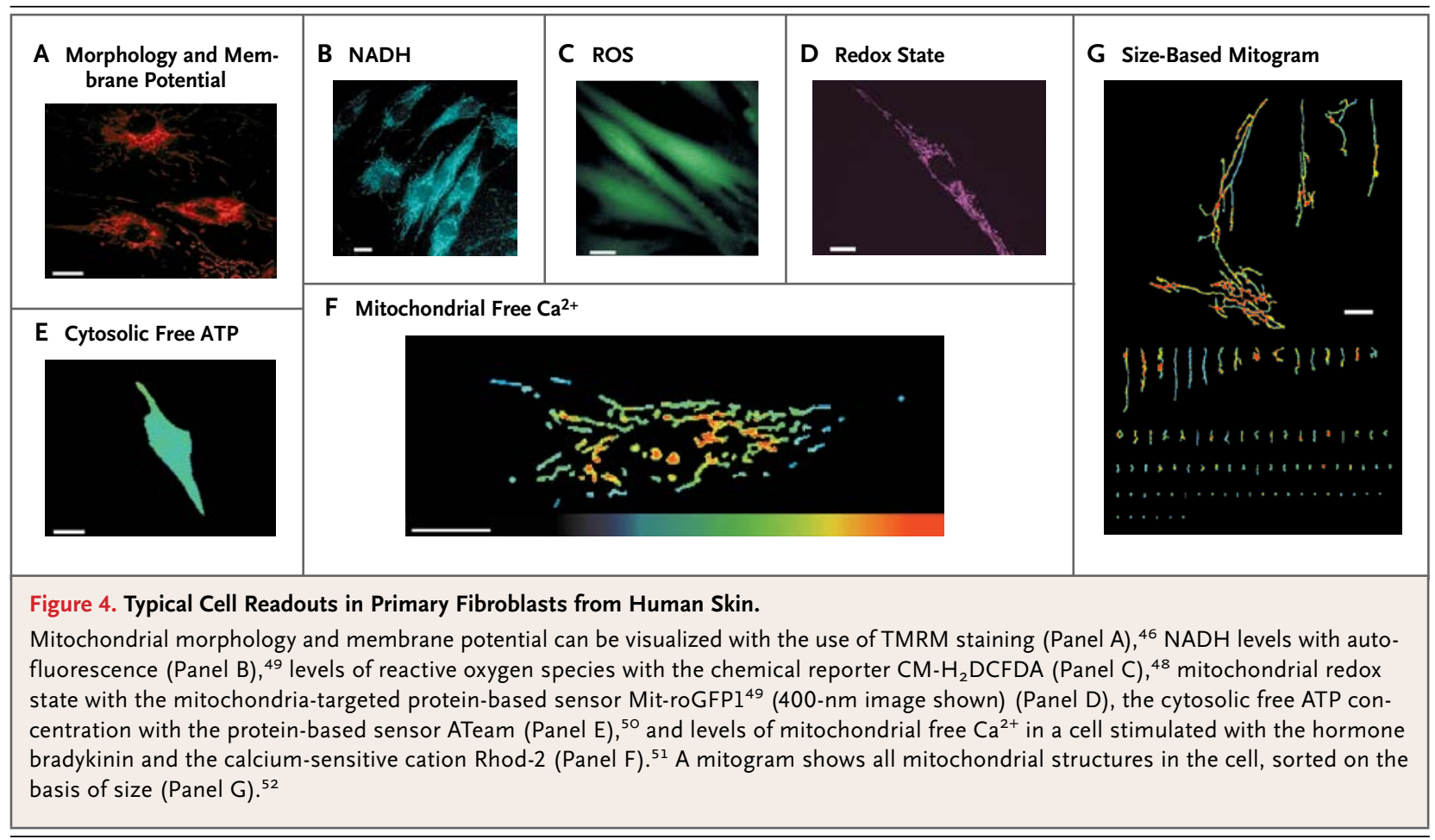

one study, investigators found that a ketogenic diet was effective in preventing epileptic seizures in children with electron-transport-chain defects. ${ }^{79}$ The findings in another study indicated that nutritional modulation affects mitochondrial function, suggesting that it may be worthwhile to pursue nutritional treatment strategies. ${ }^{64}$

A successful treatment strategy has been developed for patients with a secondary mitochondrial disorder involving Ullrich's congenital muscular dystrophy and Bethlem's myopathy. ${ }^{80-82}$ These myopathies, caused by mutations in the extracellular-matrix protein collagen VI, are associated with mitochondrial dysfunction and muscle-cell apoptosis. The pathogenic mechanism involves inappropriate opening of the mitochondrial permeability transition pore. This action was prevented in patients treated with a permeabilitytransition-pore desensitizer, cyclosporin A. Another study showed that cyclosporin A reduced the size of myocardial infarcts during cardiac reperfusion. ${ }^{83}$ Other published intervention strategies are summarized in Table 2 in the Supplementary Appendix.

An overview of current clinical trials can be found online (www.clinicaltrials.gov/ct2/results? term-mitochondrial+disease); these include studies of $\mathrm{CoQ}_{10}$ for the treatment of muscle weakness and mitochondrial diseases, dietary supplements for MELAS (mitochondrial encephalomyopathy, lactic acidosis, and strokelike episodes), EPI-743 for mitochondrial diseases, human growth hormone for obesity, nutritional therapy for diabetes, pioglitazone for diabetes, idebenone for MELAS, and vitamin $\mathrm{E}$ for mitochondrial trifunctional protein deficiency.

FUTURE PERSPECTIVES

A field that began more than 50 years ago, when a physician detected a mitochondrial disorder in a single patient with hypermetabolism, ${ }^{84}$ has now evolved into the discipline of mitochondrial medicine. Lessons learned from studies of rare diseases have implications for a broad range of medical disciplines. Within the next few years, the application of new technologies such as whole-exome sequencing can be expected to result in a huge expansion of the number of known causative nuclear gene defects in patients with mitochondrial disease (which is currently diagnosed by means of biochemical methods, mtDNA and nDNA se- 


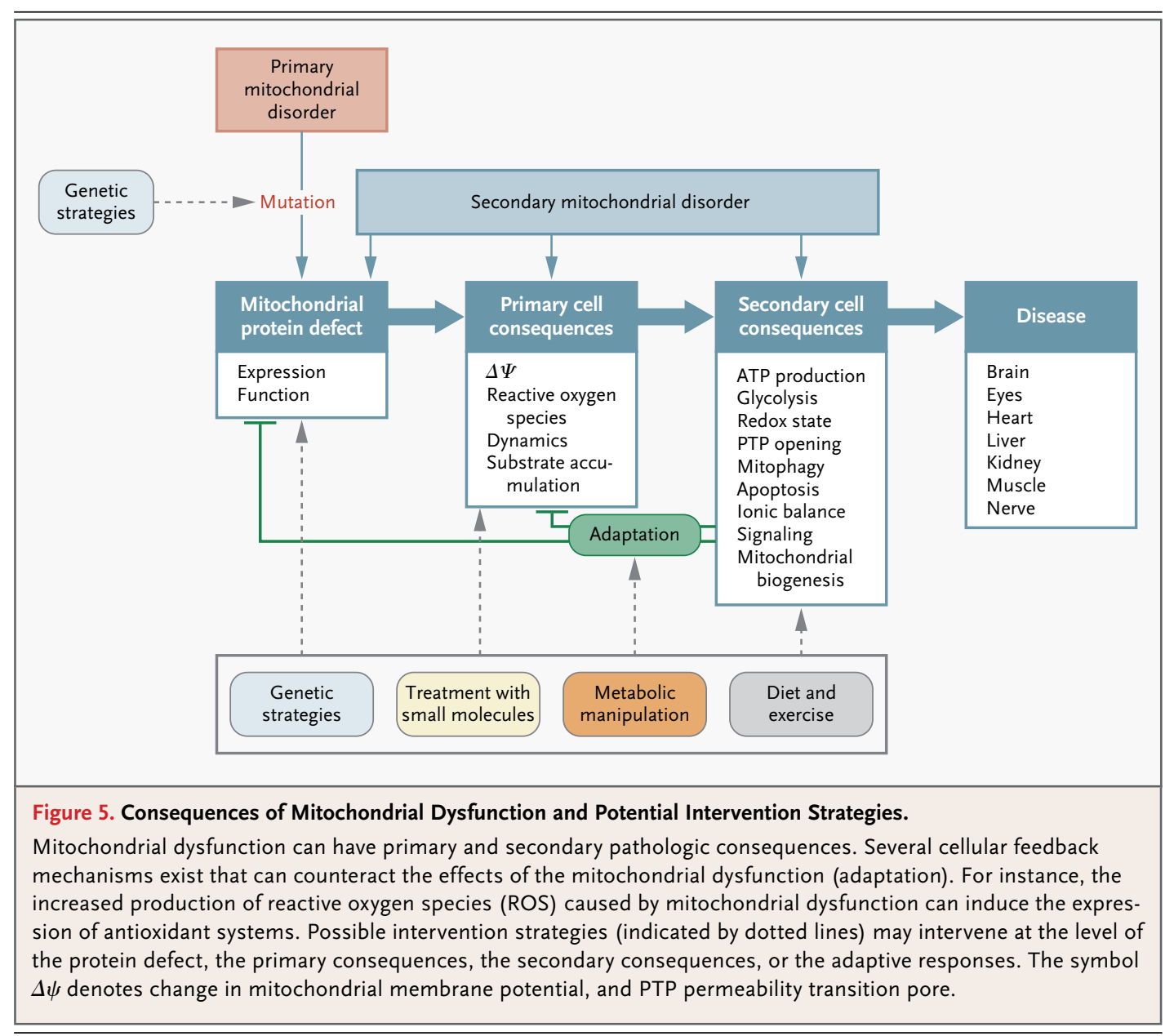

quencing, and candidate-gene studies). In the near future, the challenge will be to increase our understanding of the consequences of mitochondrial dysfunction at all levels of complexity in order to drive the development of rational treatment strategies. Although gene therapy has been proved beneficial, its use is still limited by the sheer number of potential mitochondrial gene defects. Direct enzyme-replacement therapy may be feasible in addressing single-protein enzymes, such as those in the tricarboxylic acid cycle, and perhaps mitochondrial multiprotein enzyme complexes. Another promising approach may be indirect enzyme-replacement therapy, which bypasses electron-transport defects with the use of alternative dehydrogenases or oxidases (see Table 2 in the Supplementary Appendix). Although more experimental data are required, exogenous stimulation of endogenous cellular adaptation programs may also be useful to at least partially counterbalance the consequences of mitochondrial dysfunction.

Given the metabolic individuality in humans, ${ }^{85}$ we do not expect monotherapeutic metabolic manipulation strategies to be a magic bullet but predict that the next step in treatment development will be the use of combinations of manipulation strategies applied in an individualized way. In the meantime, efforts must be made on a global scale to genetically categorize patient cohorts, monitor them in a standardized way by means of prognostic scoring systems, ${ }^{86}$ and develop new biomarkers to allow for proper monitoring of the effect of intervention strategies.

Disclosure forms provided by the authors are available with the full text of this article at NEJM.org.

We thank Dr. J. Fransen, Department of Cell Biology, Radboud University Nijmegen Medical Center, for providing electronmicroscopical images. 
REFERENCES

1. Azzu V, Brand MD. The on-off switches of the mitochondrial uncoupling proteins. Trends Biochem Sci 2010;35:298-307. 2. Cardoso AR, Queliconi BB, Kowaltowski AJ. Mitochondrial ion transport pathways: role in metabolic diseases. Biochim Biophys Acta 2010;1797:832-8.

3. West AP, Shadel GS, Ghosh S. Mitochondria in innate immune responses. Nat Rev Immunol 2011;11:389-402.

4. Murphy MP, Holmgren A, Larsson NG, et al. Unraveling the biological roles of reactive oxygen species. Cell Metab 2011; 13:361-6.

5. Spencer SL, Sorger PK. Measuring and modeling apoptosis in single cells. Cell 2011;144:926-39.

6. Scarpulla RC. Transcriptional paradigms in mammalian mitochondrial biogenesis and function. Physiol Rev 2008; 88:611-38.

7. Shutt TE, Shadel GS. A compendium of human mitochondrial gene expression machinery with links to disease. Environ Mol Mutagen 2010;51:360-79.

8. Coskun P, Wyrembak J, Schriner S, et al. A mitochondrial etiology of Alzheimer and Parkinson disease. Biochim Biophys Acta 2011 August 16 (Epub ahead of print). 9. McCoy MK, Cookson MR. Mitochondrial quality control and dynamics in Parkinson's disease. Antioxid Redox Signal 2011 July 7 (Epub ahead of print).

10. Cairns RA, Harris IS, Mak TW. Regulation of cancer cell metabolism. Nat Rev Cancer 2011;11:85-95.

11. Hoppel CL, Tandler B, Fujioka H, Riva A. Dynamic organization of mitochondria in human heart and in myocardial disease. Int J Biochem Cell Biol 2009; 41:1949-56.

12. Sleigh A, Raymond-Barker P, Thackray $\mathrm{K}$, et al. Mitochondrial dysfunction in patients with primary congenital insulin resistance. J Clin Invest 2011;121:2457-61. 13. Lönnqvist $T$, Paetau A, Valanne L, Pihko H. Recessive twinkle mutations cause severe epileptic encephalopathy. Brain 2009; 132:1553-62.

14. Mochel F, Haller RG. Energy deficit in Huntington disease: why it matters. J Clin Invest 2011;121:493-9.

15. Tseng YH, Cypess AM, Kahn CR. Cellular bioenergetics as a target for obesity therapy. Nat Rev Drug Discov 2010;9:46582.

16. Bishop NA, Lu T, Yankner BA. Neural mechanisms of ageing and cognitive decline. Nature 2010;464:529-35.

17. Finsterer J, Segall L. Drugs interfering with mitochondrial disorders. Drug Chem Toxicol 2010;33:138-51.

18. Cohen BH. Pharmacologic effects on mitochondrial function. Dev Disabil Res Rev 2010;16:189-99.

19. Dimauro S, Rustin P. A critical approach to the therapy of mitochondrial respiratory chain and oxidative phosphor- ylation diseases. Biochim Biophys Acta 2009;1792:1159-67.

20. Luft $\mathrm{R}$. The development of mitochondrial medicine. Proc Natl Acad Sci U S A 1994;91:8731-8.

21. Swerdlow RH. Mitochondrial medicine and the neurodegenerative mitochondriopathies. Pharmaceuticals (Basel) 2009;2: 150-67.

22. Benard G, Rossignol R. Ultrastructure of the mitochondrion and its bearing on function and bioenergetics. Antioxid Redox Signal 2008;10:1313-42.

23. Westermann B. Mitochondrial fusion and fission in cell life and death. Nat Rev Mol Cell Biol 2010;11:872-84.

24. Dieteren CEJ, Gielen SCAM, Nijtmans LGJ, et al. Solute diffusion is hindered in the mitochondrial matrix. Proc Natl Acad Sci U S A 2011;108:8657-62.

25. Bastin J, Lopes-Costa A, Djouadi F Exposure to resveratrol triggers pharmacological correction of fatty acid utilization in human fatty acid oxidation-deficient fibroblasts. Hum Mol Genet 2011;20:204857.

26. Smeitink JAM, van den Heuvel L, DiMauro S. The genetics and pathology of oxidative phosphorylation. Nat Rev Genet 2001;2:342-52.

27. Koopman WJH, Nijtmans LGJ, Dieteren CEJ, et al. Mammalian mitochondrial complex I: biogenesis, regulation, and reactive oxygen species generation. Antioxid Redox Signal 2010;12:1431-70.

28. Pagliarini DJ, Calvo SE, Chang B, et al. A mitochondrial protein compendium elucidates complex I disease biology. Cell 2008;134:112-23.

29. Wang C, Liu X, Wei B. Mitochondrion an emerging platform critical for host antiviral signaling. Expert Opin Ther Targets 2011;15:647-65.

30. Dimauro S, Schon EA. Mitochondrial disorders in the nervous system. Annu Rev Neurosci 2008;31:91-123.

31. Tyynismaa H, Suomalainen A. Mouse models of mitochondrial DNA defects and their relevance for human disease. EMBO Rep 2009;10:137-43.

32. Wallace DC, Fan W. The pathophysiology of mitochondrial disease as modeled in the mouse. Genes Dev 2009;23:1714-36.

33. Gredilla R, Bohr VA, Stevnsner T. Mitochondrial DNA repair and association with aging - an update. Exp Geronto 2010;45:478-88.

34. Swerdlow RH. Does mitochondria DNA play a role in Parkinson's disease? A review of cybrid and other supportive evidence. Antioxid Redox Signal 2011 May 25 (Epub ahead of print).

35. Yarham JW, Elson JL, Blakely EL, McFarland R, Taylor RW. Mitochondria tRNA mutations and disease. Wiley Interdiscip Rev RNA 2010;1:304-24.

36. Erol A. Deciphering the intricate regulatory mechanisms for the cellular choice between cell repair, apoptosis or senescence in response to damaging signals. Cell Signal 2011;23:1076-81.

37. Kourtis N, Tavernarakis N. Cellular stress response pathways and ageing: intricate molecular relationships. EMBO J 2011; 30:2520-31.

38. Twig G, Shirihai OS. The interplay between mitochondrial dynamics and mitophagy. Antioxid Redox Signal 2011;14: 1939-51.

39. Youle RJ, Narendra DP. Mechanisms of mitophagy. Nat Rev Mol Cell Biol 2011; 12:9-14.

40. Rossignol R, Faustin B, Rocher C, Malgat M, Mazat JP, Letellier T. Mitochondrial threshold effects. Biochem J 2003; 370:751-62.

41. Bénit P, El-Khoury R, Schiff M, Sainsard-Chanet A, Rustin P. Genetic background influences mitochondrial function: modeling mitochondrial disease for therapeutic development. Trends Mol Med 2010;16:210-7.

42. Brand MD, Nicholls DG. Assessing mitochondrial dysfunction in cells. Biochem J 2011;435:297-312.

43. Cortassa S, Aon MA, Winslow RL, O'Rourke B. A mitochondrial oscillator dependent on reactive oxygen species. Biophys J 2004;87:2060-73.

44. Juhaszova M, Zorov DB, Kim SH, et al. Glycogen synthase kinase-3 beta mediates convergence of protection signaling to inhibit the mitochondrial permeability transition pore. J Clin Invest 2004;113: 1535-49.

45. Picard M, Taivassalo T, Ritchie D, et al. Mitochondrial structure and function are impaired by standard isolation methods. PLoS One 2011;6(3):e18317.

46. Distelmaier F, Koopman WJH, Testa $\mathrm{ER}$, et al. Life cell quantification of mitochondrial membrane potential at the single organelle level. Cytometry A 2008;73: 129-38.

47. Distelmaier F, Koopman WJH, van den Heuvel LP, et al. Mitochondrial complex I deficiency: from organelle dysfunction to clinical disease. Brain 2009;132: 833-42.

48. Forkink M, Smeitink JAM, Brock R, Willems PH, Koopman WJ. Detection and manipulation of mitochondrial reactive oxygen species in mammalian cells. Biochim Biophys Acta 2010;1797:1034-44.

49. Verkaart S, Koopman WJH, Cheek J, et al. Mitochondrial and cytosolic thiol redox state are not detectably altered in isolated human NADH:ubiquinone oxidoreductase deficiency. Biochim Biophys Acta 2007;1772:1041-51.

50. Imamura $\mathrm{H}$, Nhat $\mathrm{KP}$, Togawa $\mathrm{H}$, et al. Visualization of ATP levels inside single living cells with fluorescence resonance energy transfer-based genetically encoded indicators. Proc Natl Acad Sci U S A 2009;106:15651-6 
51. Koopman WJH, Distelmaier F, Esseling JJ, Smeitink JA, Willems PH. Computerassisted live cell analysis of mitochondrial membrane potential, morphology and calcium handling. Methods 2008;46:304-11. 52. Koopman WJH, Visch HJ, Verkaart $S$, van den Heuvel LW, Smeitink JA, Willems $\mathrm{PH}$. Mitochondrial network complexity and pathological decrease in complex I activity are tightly correlated in isolated human complex I deficiency. Am J Physiol Cell Physiol 2005;289:C881-C890.

53. Koopman WJH, Verkaart S, Visch HJ et al. Human NADH:ubiquinone oxidoreductase deficiency: radical changes in mitochondrial morphology? Am J Physiol Cell Physiol 2007;293:C22-C29.

54. Koopman WJH, Verkaart S, van Emst-de Vries SE, et al. Mitigation of NADH:ubiquinone oxidoreductase deficiency by chronic Trolox treatment. Biochim Biophys Acta 2008;1777:853-9.

55. Koene S, Smeitink JAM. Metabolic manipulators: a well founded strategy to combat mitochondrial dysfunction. J Inherit Metab Dis 2010;34:315-25.

56. Valsecchi F, Koopman WJH, Manjeri GR, Rodenburg RJ, Smeitink JA, Willems PH. Complex I disorders: causes, mechanisms, and development of treatment strategies at the cellular level. Dev Disabil Res Rev 2010;16:175-82.

57. Roestenberg P, Manjeri GR, Valsecchi F, Smeitink JA, Willems PH, Koopman WJ. Pharmacological targeting of mitochondrial complex I deficiency: the cellular level and beyond. Mitochondrion 2012;12:5765 .

58. Blanchet L, Buydens LMC, Smeitink JAM, et al. Isolated mitochondrial complex I deficiency: explorative data analysis of patient cell parameters. Curr Pharm Des 2011;17:4023-33.

59. Zanella F, Lorens JB, Link W. High content screening: seeing is believing. Trends Biotechnol 2010;28:237-45.

60. Kruse SE, Watt WC, Marcinek DJ, Kapur RP, Schenkman KA, Palmiter RD. Mice with mitochondrial complex I deficiency develop a fatal encephalomyopathy. Cell Metab 2008;7:312-20.

61. Koene S, Willems PHGM, Roestenberg P, Koopman WJ, Smeitink JA. Mouse models for nuclear DNA-encoded mitochondrial complex I deficiency. J Inherit Metab Dis 2011;34:293-307.
62. Schmidt S, Linnartz B, Mendritzki S, et al. Genetic mouse models for Parkinson's disease display severe pathology in glial cell mitochondria. Hum Mol Genet 2011; 20:1197-211.

63. Wallace DC, Fan W, Procaccio V. Mitochondrial energetics and therapeutics. Annu Rev Pathol 2010;5:297-348.

64. Schiff M, Bénit P, Coulibaly A, Loublier S, El-Khoury R, Rustin P. Mitochondrial response to controlled nutrition in health and disease. Nutr Rev 2011;69:65-79.

65. Camara AKS, Lesnefsky EJ, Stowe DF. Potential therapeutic benefits of strategies directed to mitochondria. Antioxid Redox Signal 2010;13:279-347.

66. Wenz T, Williams SL, Bacman SR, Moraes CT. Emerging therapeutic approaches to mitochondrial diseases. Dev Disabil Res Rev 2010;16:219-29.

67. Craven L, Elson J, Irving L, et al. Mitochondrial DNA diseases: new options for prevention. Hum Mol Genet 2011;20:R168R174.

68. Yousif LF, Stewart KM, Horton KL, Kelley SO. Mitochondria-penetrating peptides: sequence effects and model cargo transport. Chembiochem 2009;10:2081-8. 69. Chacko BK, Reily C, Srivastava A, et al. Prevention of diabetic nephropathy in Ins2(+/)- (Akita) mice by the mitochondria-targeted therapy MitoQ. Biochem J 2010;432:9-19.

70. Shokolenko IN, Alexeyev MF, LeDoux SP, Wilson GL. The approaches for manipulating mitochondrial proteome. Environ Mol Mutagen 2010;51:451-61.

71. Zhang E, Zhang C, Su Y, Cheng T, Shi C. Newly developed strategies for multifunctional mitochondria-targeted agents in cancer therapy. Drug Discov Today 2011; 16:140-6.

72. Skulachev MV, Antonenko YN, Anisimov VN, et al. Mitochondrial-targeted plastoquinone derivatives: effect on senescence and acute age-related pathologies. Curr Drug Targets 2011;12:800-26.

73. Smith RA, Hartley RC, Murphy MP. Mitochondria-targeted small molecule therapeutics and probes. Antioxid Redox Signal 2011;15:3021-38.

74. Won YW, Lim KS, Kim YH. Intracellular organelle-targeted non-viral gene delivery systems. J Control Release 2011; 152:99-109.

75. Rapoport M, Salman L, Sabag O, Patel
MS, Lorberboum-Galski H. Successful TATmediated enzyme replacement therapy in a mouse model of mitochondrial E3 deficiency. J Mol Med (Berl) 2011;89:161-70.

76. Chinnery P, Majamaa K, Turnbull D, Thorburn D. Treatment for mitochondrial disorders. Cochrane Database Syst Rev 2006;1:CD004426.

77. Stacpoole PW. Why are there no proven therapies for genetic mitochondrial diseases? Mitochondrion 2011;11:679-85.

78. Klopstock T, Yu-Wai-Man P, Dimitriadis $\mathrm{K}$, et al. A randomized placebo-controlled trial of idebenone in Leber's hereditary optic neuropathy. Brain 2011;134:2677-86.

79. Kang HC, Lee YM, Kim HD, Lee JS, Slama A. Safe and effective use of the ketogenic diet in children with epilepsy and mitochondrial respiratory chain complex defects. Epilepsia 2007;48:82-8.

80. Irwin WA, Bergamin N, Sabatelli P, et al. Mitochondrial dysfunction and apoptosis in myopathic mice with collagen VI deficiency. Nat Genet 2003;35:367-71.

81. Angelin A, Tiepolo T, Sabatelli P, et al. Mitochondrial dysfunction in the pathogenesis of Ullrich congenital muscular dystrophy and prospective therapy with cyclosporins. Proc Natl Acad Sci U S A 2007;104:991-6.

82. Merlini L, Angelin A, Tiepolo T, et al. Cyclosporin A corrects mitochondrial dysfunction and muscle apoptosis in patients with collagen VI myopathies. Proc Natl Acad Sci U S A 2008;105:5225-9.

83. Piot C, Croisille P, Staat P, et al. Effect of cyclosporine on reperfusion injury in acute myocardial infarction. $\mathrm{N}$ Engl J Med 2008;359:473-81.

84. Luft R, Ikkos D, Palmieri G, Ernster L, Afzelius B. A case of severe hypermetabolism of nonthyroid origin with a defect in the maintenance of mitochondrial respiratory control: a correlated clinical, biochemical, and morphological study. J Clin Invest 1962;41:1776-804.

85. Suhre K, Shin SY, Petersen AK, et al. Human metabolic individuality in biomedical and pharmaceutical research. Nature 2011;477:54-60.

86. Morava E, van den Heuvel L, Hol F, et al. Mitochondrial disease criteria: diagnostic applications in children. Neurology 2006;67:1823-6.

Copyright (๑) 2012 Massachusetts Medical Society. 